\title{
Psychrometrical investigations
}

\section{J.M. Pernter}

To cite this article: J.M. Pernter (1884) Psychrometrical investigations, Philosophical Magazine Series 5, 17:107, 412-412, DOI: 10.1080/14786448408627537

To link to this article: http://dx.doi.org/10.1080/14786448408627537

曲 Published online: 29 Apr 2009.

6 Submit your article to this journal $\pi$

LII Article views: 3

Q View related articles $₫$ 
III. For an amateur the following experiment will appear rather strange, in which the quality of a strange voice will seem changed by the resonance of the cavity of the mouth. One end of the india-rubber tube is again placed in the ear and the other in the mouth; the mouth is put in the various positions for $a, 0, \ddot{a}$, while another person sings or draws out a definite sound such as $a$. With a suitable height of the voice speaking; according to the position of the mouth, the vowels $a, o, \ddot{a}$ are successively heard.Wiedemann's Annalen, No. 3, 1884.

PSYCHROMETRICAL INVESTIGATIONS. BX J. M. PERNTER.

Pernter has made psychrometrical observations on the Obir (6722 feet above the sea-level) with Wild's ventilation-hygrometer, Regnault's dew-point hygrometer, and Schwackhofer's volumetric hygrometer. These observations and the theoretical considerations connected therewith lead to the following results:-

1. The development of the psychrometer formula under the assumption of convection does not lead to the goal, for the assumption that the inflowing air is cooled by the wet-thermometer bulb from $t$ to $t^{\prime}$ does not hold.

2. The investigation of the psychrometer formula by Maxwell and Stefan for perfectly still air is quite correct for this condition. It loses in exactitude if modified for air in motion; but it gives the following very close approximation, if we represent by the expression $v /(t-t$ ' +1$)$ the "inertia" of the psychrometer when near saturation (that is, the fact that with moist air the evaporation is not rapid enough in comparison with the inflowing air):-

$$
p_{0}=p_{1}-\mathrm{P} \frac{\mathrm{S}}{\lambda \sigma}\left\{\frac{k^{\prime}}{\mathrm{D}}+\frac{r \mathrm{R}}{a \mathrm{D} \mu \sigma}\right\}\left\{\left(t-t^{\prime}\right)+\frac{v}{\left(t-t^{\prime}\right)+1}\right\} ;
$$

or making $v=0^{\circ .5} \mathrm{C}$. and inserting the numerical values,

$$
p_{0}=p_{2}-\mathrm{P} \cdot 0 \cdot 00063\left\{1+\frac{1}{a}\right\}\left\{\left(t-t_{1}\right)+\frac{0 \cdot 5}{t-t^{\prime}+1}\right\} \text {. }
$$

3. The meraber which depends on the radiation does not disappear, therefore, even with air in violent motion; with still air it is as great as that depending on conduction.

4. The constant a does not change for equal velocity of the air and for equal pressure. With lower pressure it is smaller, and probably in the ratio $P / 760$. For 760 millim. we get for $a$ the value $a_{2}=3 \cdot 0$, and therefore for any given pressure $\mathrm{P}: a=3 \mathrm{P} / 760$.

5. The general result is that an exact formula for the psychrometer can scarcely be obtained, and that therefore we cannot expect by means of the psychrometer to determine the pressure of vapour to within 0.1 millim.-Beiblätter der Physik, vol. viii. p. 31. 